\title{
A Phase I/Randomized Phase II Study to Evaluate the Safety, Pharmacokinetics, and Efficacy of Nintedanib versus Sorafenib in Asian Patients with Advanced Hepatocellular Carcinoma
}

\author{
Chia-Jui Yen ${ }^{a}$ Tae-You Kim $^{b}$ Yin-Hsun Feng ${ }^{c}$ Yee Chaod Deng-Yn Lin ${ }^{\text {e }}$ \\ Baek-Yeol Ryoo ${ }^{f}$ Dennis Chin-Lun Huang ${ }^{g}$ David Schnell $^{\text {h }}$ Julia Hocke ${ }^{\text {h }}$ \\ Arsène-Bienvenu Loembé ${ }^{i} \quad$ Ann-Lii Cheng ${ }^{j, k}$ \\ a Division of Hematology and Oncology, Department of Internal Medicine, National \\ Cheng Kung University Hospital, College of Medicine, National Cheng Kung University, \\ Tainan, Taiwan; ${ }^{b}$ Seoul National University Hospital, Seoul, South Korea; ${ }^{c}$ Chi Mei Medical \\ Center, Yongkang, Tainan, Taiwan; d Taipei Veterans General Hospital, Taipei, Taiwan; \\ e Chang Gung Memorial Hospital \& Chang Gung University, College of Medicine, Taoyuan, \\ Taiwan; ${ }^{f}$ Asan Medical Center, University of Ulsan College of Medicine, Seoul, South Korea;

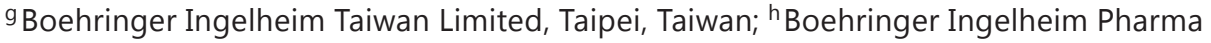 \\ GmbH \& Co. KG, Ingelheim am Rhein, Germany; 'Boehringer Ingelheim B.V., Alkmaar, \\ The Netherlands; ${ }^{j}$ National Taiwan University Hospital, Taipei, Taiwan; ${ }^{k}$ National Taiwan \\ University Cancer Center, Taipei, Taiwan
}

\section{Keywords}

Nintedanib · Sorafenib · Advanced hepatocellular carcinoma · Angiokinase inhibitor .

Dose-limiting toxicity - Maximum tolerated dose

\begin{abstract}
Background: Nintedanib is an oral, triple angiokinase inhibitor of vascular endothelial growth factor/platelet-derived growth factor/fibroblast growth factor receptors. This randomized, multicenter, open-label, phase I/II study evaluated the safety, pharmacokinetics, maximum tolerated dose (MTD) in terms of dose-limiting toxicities (DLTs), and efficacy of nintedanib versus sorafenib in Asian patients with unresectable advanced hepatocellular carcinoma (HCC). Patients and Methods: For the phase I portion, patients were stratified into two groups according to their alanine aminotransferase/aspartate aminotransferase (ALT/AST) and ChildPugh score at baseline. For phase I, the primary endpoint was determination of the MTD in terms of DLTs. For phase II, patients with a Child-Pugh score of 5-6, an Eastern Cooperative
\end{abstract}


Oncology Group performance score $\leq 2$, and an ALT/AST $\leq 2 \times$ the upper limit of normal were enrolled and randomized 2:1 to nintedanib $200 \mathrm{mg}$ twice daily (b.i.d.) (the MTD determined in phase I) or sorafenib $400 \mathrm{mg}$ b.i.d. continuously in 28-day cycles until intolerable adverse events (AEs) or disease progression (PD); treatment beyond PD was allowed if clinical benefit was perceived. The primary endpoint for phase II was time to progression (TTP) by central independent review (CIR; by Response Evaluation Criteria in Solid Tumors v1.0); the secondary endpoints included overall survival (OS). All analyses were exploratory. Results: The MTD was $200 \mathrm{mg}$ in both groups. For phase II, 95 patients were randomized to nintedanib $(n=63)$ or sorafenib $(n=32)$. For nintedanib and sorafenib, respectively, the median CIR TTP was 2.8 vs. 3.7 months (hazard ratio $[\mathrm{HR}]=1.21,95 \%$ confidence interval $[\mathrm{CI}] 0.73-2.01$ ) and the median OS 10.2 vs. 10.7 months (HR $=0.94,95 \%$ CI 0.59-1.49). Nintedanib-treated patients had fewer grade 3 or higher AEs ( 56 vs. $84 \%$ ), serious AEs (46 vs. $56 \%$ ), and AEs leading to dose reduction (19 vs. $59 \%$ ) and drug discontinuation ( 24 vs. $34 \%$ ). AEs associated more frequently with nintedanib were vomiting and nausea, whereas those associated more frequently with sorafenib were ALT/AST increases, diarrhea, rash, and palmar-plantar erythrodysesthesia syndrome. Conclusions: Nintedanib showed numerically similar efficacy to sorafenib for CIR TTP and OS in Asian patients with advanced HCC and adequate liver function. AEs were generally manageable.

(C) 2018 S. Karger AG, Basel

\section{Introduction}

Globally and in the Asia-Pacific region, liver cancer is one of the top three causes of cancer death $[1,2]$. Hepatocellular carcinoma (HCC), the most common form of liver cancer [3], is most commonly associated with chronic hepatitis B virus (HBV) or hepatitis C virus (HCV) infections [3]. Worldwide, approximately three-quarters of people infected with HBV are Asian [3], and in most Asian countries, chronic HBV infection underlies the etiology of 70-80\% of HCC cases [2].

HCC is a hypervascular tumor [4] involving dysregulation of several angiogenic growth factors such as vascular endothelial growth factor (VEGF) [5-7], epidermal growth factor [5-7], platelet-derived growth factor (PDGF) [5-7], and fibroblast growth factor (FGF) [8]. Sorafenib, a small-molecule kinase inhibitor of VEGFR, PDGFR, RAF, c-KIT, and FLT-3, is the only targeted drug approved worldwide for the first-line treatment of advanced HCC. In pivotal phase III trials in Western [9] and Asian patients [1], sorafenib was shown to result in significantly improved overall survival (OS) compared to that achieved with placebo. However, the effect of sorafenib in HCC is modest, with a median OS prolongation of 2.3 months for patients in the Asia-Pacific region compared to placebo, and treatment is accompanied by significant toxicity [1]. Different risk factors and etiologies between Western and Asian populations, such as different rates of HBV and HCV infection, could account for important differences in responses to targeted therapies $[10,11]$. Consequently, there is a continued need for development of targeted drugs that might provide more sustained or equivalent disease control and survival benefit and have a better or different adverse event (AE) profile than sorafenib in advanced HCC.

Nintedanib is an oral, small-molecule, triple angiokinase inhibitor of VEGFR1-3, PDGFR $\alpha$ and $\beta$, FGFR1-3, FLT-3, Lck, Lyn, and Src [12], with antitumor and antiangiogenic activity in preclinical models of HCC [13]. Nintedanib is metabolized in the liver [14], and thus the safety and pharmacokinetics (PK) of nintedanib in patients with liver impairment may be different from those in patients with preserved liver function. Moreover, the safety and PK of nintedanib may be different in Asian patients than in Caucasian patients with advanced HCC. 


\section{Liver Cancer}

\begin{tabular}{l|l}
\hline Liver Cancer \\
\hline DOI: 10.1159/000486460 & $\begin{array}{l}\text { @ 2018 S. Karger AG, Basel } \\
\text { www.karger.com/lic }\end{array}$ \\
\hline
\end{tabular}

Yen et al.: Nintedanib versus Sorafenib in Asian Patients

Nintedanib was approved in Europe, in combination with docetaxel, after first-line chemotherapy, for advanced, metastatic, or locally recurrent non-small-cell lung cancer tumors of adenocarcinoma histology.

We report the results of a randomized, multicenter, open-label phase I/II trial that evaluated the maximum tolerated dose (MTD) of nintedanib in terms of dose-limiting toxicities (DLTs), PK, safety, and efficacy of nintedanib versus sorafenib in Asian patients with advanced HCC (ClinicalTrials.gov registration: NCT00987935; trial identification number: 1199.39). A similarly designed trial conducted with mostly Caucasians is reported separately (ClinicalTrials.gov registration: NCT01004003; trial identification number: 1199.37) (unpublished data).

\section{Patients and Methods}

Study Population and Eligibility

The key inclusion criteria included: age $\geq 18$ years; advanced HCC not amenable to curative/locoregional therapy and with $\geq 1$ measurable lesion by Response Evaluation Criteria in Solid Tumors (RECIST) v1.0 (for phase II); Eastern Cooperative Oncology Group performance score $\leq 2$; Child-Pugh score 5-6 (class A) and alanine aminotransferase/aspartate aminotransferase (ALT/AST) levels $\leq 2$ times the upper limit of normal (ULN) (for phase II and phase I group I; phase I group II had ALT or AST $>2$ to $\leq 5$ times the ULN or Child-Pugh score 7); >4 weeks since most recent local therapy; no prior systemic therapy for HCC, except in phase I, where 1 prior line was allowed; no history of other malignancy within the past 3 years; and life expectancy $\geq 12$ weeks. Patients with serum creatinine and/or bilirubin $>1.5$ times the ULN were excluded.

\section{Study Design and Treatment}

This was a phase I/II trial in which patients were initially stratified into two groups for phase I (group I: ALT and AST $\leq 2$ times the ULN and Child-Pugh score 5-6; group II: ALT or AST $>2$ to $\leq 5$ times the ULN or Child-Pugh score 7), with patients from both to be included in phases I and II. Following a protocol amendment, it was decided to proceed only with patients from group I in phase II because the MTD was reached sooner in that group and recruitment in group II was very slow owing to lack of eligible patients. For phase II, 95 patients were randomized 2:1 to receive nintedanib $200 \mathrm{mg}$ twice daily (b.i.d.) $(n=63)$ or sorafenib $400 \mathrm{mg}$ b.i.d. $(n=32)$ continuously, in 28-day cycles, until intolerable AEs or disease progression (PD). When the trial was conceived, more data on nintedanib, especially regarding safety, were sought; a small active comparator group, using a 2:1 randomization ratio, was therefore chosen to allow direct comparison (rather than performing an uncontrolled study, which was common at the time). Treatment beyond PD was allowed at the discretion of the investigator.

The MTD determination methods and the DLT definitions for nintedanib are presented in the online supplementary material (for all online suppl. material, see www.karger.com/doi/10.1159/000486460).

Extensive plasma and urine sampling was performed during the first treatment course to describe the PK characteristics of nintedanib and its metabolites BIBF 1202 and BIBF 1202 glucuronide. Assessments were performed according to the schedule shown in the online supplementary material.

Randomization was performed by an integrated response system using a validated randomization number-generating system. Patient randomization was stratified by presence of extrahepatic spread (EHS) and macrovascular invasion (MVI) (EHS and/or MVI present vs. both absent). The full details of randomization, as well as the dose reduction scheme and trial procedures and assessments, are shown in the online supplementary material. Antiviral treatment was recommended for patients with chronic HBV infection.

Study Outcomes

The primary endpoints for phase I and II, respectively, were determination of MTD in terms of DLTs and time to progression (TTP) by central independent review (CIR) according to RECIST v1.0.

The main secondary endpoints for phase II were objective tumor response according to RECIST v1.0 assessed by CIR, defined as a best response of complete response or partial response, progression-free survival (PFS) assessed by CIR, and OS. Definitions and further outcome measures are described in the online supplementary material. 
Yen et al.: Nintedanib versus Sorafenib in Asian Patients

\section{Pharmacokinetic Sampling}

For quantification of nintedanib, BIBF 1202, and BIBF 1202 glucuronide plasma concentrations, $5 \mathrm{~mL}$ of blood was taken from a forearm vein in an EDTA-anticoagulant blood drawing tube at the following time points in the first treatment course (days 15-16): immediately prior to swallowing the dose of nintedanib (predose) and 1, 2, 3, 4, 5, 7, 10, 12 (allowed time frame 11-13 h), and $24 \mathrm{~h}$ (allowed time frame 22-26 h) after drug administration on day 15 (the evening dose on day 15 was omitted).

Urine was sampled at the following intervals: $0-4 \mathrm{~h}, 4-12 \mathrm{~h}$, and $12-24 \mathrm{~h}$ after nintedanib administration on day 15-16. The urine weight/volume for each collection interval was documented, and 2-mL aliquots were stored for bioanalytical measurement.

Plasma and urine concentrations of nintedanib (in the form of its free base BIBF 1120 BS), its metabolite BIBF 1202 (in the form of the free zwitterion BIBF 1202 ZW), and the acyl glucuronide thereof (BIBF 1202 glucuronide) were determined by validated assays based on liquid chromatography-tandem mass spectrometry.

For the evaluation of nintedanib plasma protein binding, 10-mL blood samples were collected in devices coated with EDTA before the very first drug administration. In vitro protein binding was determined by means of equilibrium dialysis using radiolabeled compound (non-Good Laboratory Practice).

\section{Statistical Analysis}

For both phases, the treated set included all patients who received at least one single dose of nintedanib and was used for safety and efficacy analyses. The PK set, which was used for all PK analyses, included all evaluable patients in the treated set who provided at least one observation for at least one PK endpoint without important protocol violations relevant to the evaluation of PK. All safety and PK analyses were descriptive and exploratory. No per-protocol population was used for the safety and efficacy analyses (an intent-to-treat approach was used) although important protocol violations were described.

For phase II, TTP, OS, and PFS were assessed based on the Kaplan-Meier method for each group separately; point estimates, together with confidence intervals (CIs) (based on the Brookmeyer and Crowley method), were provided for median TTP, median OS, and median PFS. Estimates of the effect of nintedanib versus sorafenib treatment on TTP, OS, and PFS were given by the hazard ratio (HR) and its 95\% CI using a stratified Cox proportional hazard model. Sample size calculations are presented in the online supplementary material.

WinNonlin 5.2 (Certara, Princeton, NJ, USA) and SAS version 9.2 (SAS, Cary, NC, USA) were used for all statistical and PK analyses.

\section{Results}

\section{Patient Disposition and Characteristics}

For phase I, 39 patients were recruited: 10 in group I and 29 in group II, all of whom received at least one dose of nintedanib. Further phase I patient details are presented in the online supplementary material.

Of 139 enrolled patients, 95 were randomly assigned to the phase II part between April 6, 2011 to January 17, 2012, and all received at least one dose of nintedanib $(n=63)$ or sorafenib $(n=32)$, in 16 centers in Taiwan and Korea (online suppl. Fig. S1, CONSORT diagram). Baseline characteristics were well balanced between the two treatment groups except for alpha-fetoprotein (AFP) values $>20 \mu \mathrm{g} / \mathrm{L}$ (nintedanib 76.2\% vs. sorafenib 65.6\%), MVI (nintedanib 47.6\% vs. sorafenib 31.3\%), and Barcelona Clinic Liver Cancer (BCLC) stage C (nintedanib $84.1 \%$ vs. sorafenib 93.8\%) and stage B (nintedanib $14.3 \%$ vs. sorafenib 3.1\%) (Table 1). Although the presence of MVI was not balanced, the combination of MVI and EHS (EHS and/or MVI present vs. both absent) was used as a stratification factor and therefore was balanced between treatment arms. 
Table 1. Phase II patient baseline demographics and clinical characteristics

\begin{tabular}{|c|c|c|c|c|c|}
\hline \multirow[t]{2}{*}{ Characteristic } & \multicolumn{2}{|c|}{$\begin{array}{l}\text { Nintedanib } 200 \text { mg b.i.d. } \\
(n=63)\end{array}$} & \multicolumn{2}{|c|}{$\begin{array}{l}\text { Sorafenib } 400 \mathrm{mg} \text { b.i.d. } \\
(n=32)\end{array}$} & \multirow{2}{*}{$\begin{array}{l}\text { Total } \\
(N=95) \\
n(\%)\end{array}$} \\
\hline & $n$ & $\%$ & $n$ & $\%$ & \\
\hline \multicolumn{6}{|l|}{ Age, years } \\
\hline Median & \multicolumn{2}{|c|}{58.0} & \multicolumn{2}{|r|}{62.0} & 59.0 \\
\hline Range & \multicolumn{2}{|c|}{$33-84$} & \multicolumn{2}{|r|}{$32-81$} & $32-84$ \\
\hline Male sex & 57 & 90.5 & 26 & 81.3 & $83(87.4)$ \\
\hline \multicolumn{6}{|l|}{ Race } \\
\hline Korean & 21 & 33.3 & 10 & 31.3 & $31(32.6)$ \\
\hline Taiwanese & 42 & 66.7 & 22 & 68.8 & $64(67.4)$ \\
\hline \multicolumn{6}{|l|}{ Time since diagnosis, months } \\
\hline Median & \multirow{2}{*}{\multicolumn{2}{|c|}{$\begin{array}{c}7.75 \\
0.2-131.3\end{array}$}} & \multirow{2}{*}{\multicolumn{2}{|c|}{$\begin{array}{c}6.31 \\
0.1-126.4\end{array}$}} & 7.13 \\
\hline Range & & & & & $0.1-131.3$ \\
\hline \multicolumn{6}{|l|}{ ECOG performance score } \\
\hline 0 & 35 & 55.6 & 18 & 56.3 & $53(55.8)$ \\
\hline 1 & 27 & 42.9 & 14 & 43.8 & $41(43.2)$ \\
\hline 2 & 1 & 1.6 & 0 & 0 & $1(1.1)$ \\
\hline \multicolumn{6}{|l|}{ Child-Pugh score } \\
\hline 5 & 39 & 61.9 & 23 & 71.9 & $62(65.3)$ \\
\hline 6 & 24 & 38.1 & 8 & 25.0 & $32(33.7)$ \\
\hline $7^{\mathrm{a}}$ & 0 & 0 & 1 & 3.1 & $1(1.1)$ \\
\hline \multicolumn{6}{|l|}{ BCLC stage } \\
\hline A & 1 & 1.6 & 1 & 3.1 & $2(2.1)$ \\
\hline B & 9 & 14.3 & 1 & 3.1 & $10(10.5)$ \\
\hline $\mathrm{C}$ & 53 & 84.1 & 30 & 93.8 & $83(87.4)$ \\
\hline MVI & 30 & 47.6 & 10 & 31.3 & $40(42.1)$ \\
\hline EHS & 43 & 68.3 & 22 & 68.8 & $65(68.4)$ \\
\hline \multicolumn{6}{|l|}{ Location of EHS } \\
\hline Bone & 7 & 11.1 & 2 & 6.3 & $9(9.5)$ \\
\hline Lung & 25 & 39.7 & 10 & 31.3 & $35(36.8)$ \\
\hline Lymph & 24 & 38.1 & 9 & 28.1 & 33 (34.7) \\
\hline Other & 17 & 27.0 & 8 & 25.0 & $25(26.3)$ \\
\hline Etiology of parenchymal liver di & & & & & \\
\hline Alcohol related & 2 & 3.2 & 2 & 6.3 & $4(4.2)$ \\
\hline HBV infection & 40 & 63.5 & 20 & 62.5 & $60(63.2)$ \\
\hline HCV infection & 9 & 14.3 & 6 & 18.8 & $15(15.8)$ \\
\hline HBV + HCV infection & 3 & 4.8 & 0 & 0 & $3(3.2)$ \\
\hline Unknown & 8 & 12.7 & 3 & 9.4 & $11(11.6)$ \\
\hline Other & 1 & 1.6 & 1 & 3.1 & $2(2.1)$ \\
\hline Parenchymal liver disease & & & & & \\
\hline Chronic hepatitis & 17 & 27.0 & 9 & 28.1 & $26(27.4)$ \\
\hline Steatofibrosis & 0 & 0 & 0 & 0 & 0 \\
\hline Cirrhosis & 41 & 65.1 & 20 & 62.5 & $61(64.2)$ \\
\hline No evidence & 5 & 7.9 & 1 & 3.1 & $6(6.3)$ \\
\hline Unknown & 0 & 0 & 1 & 3.1 & $1(1.1)$ \\
\hline Other & 0 & 0 & 1 & 3.1 & $1(1.1)$ \\
\hline Type of local therapy & & & & & \\
\hline Complete surgical resection & 7 & 11.1 & 2 & 6.3 & $9(9.5)$ \\
\hline Radiofrequency ablation & 3 & 4.8 & 1 & 3.1 & $4(4.2)$ \\
\hline PEI & 0 & 0 & 0 & 0 & 0 \\
\hline TACE & 31 & 49.2 & 17 & 53.1 & $48(50.5)$ \\
\hline Radiotherapy & 1 & 1.6 & 1 & 3.1 & $2(2.1)$ \\
\hline Other & 9 & 14.3 & 2 & 6.3 & $11(11.6)$ \\
\hline AFP group at baseline & & & & & \\
\hline$\leq 20 \mu \mathrm{g} / \mathrm{L}$ & 15 & 23.8 & 11 & 34.4 & $26(27.4)$ \\
\hline$>20 \mu \mathrm{g} / \mathrm{L}$ & 48 & 76.2 & 21 & 65.6 & $69(72.6)$ \\
\hline Stratification group & & & & & \\
\hline I: EHS and/or MVI present & 54 & 85.7 & 28 & 87.5 & $82(86.3)$ \\
\hline II: EHS and MVI both absent & 9 & 14.3 & 4 & 12.5 & 13 (13.7) \\
\hline
\end{tabular}

AFP, alpha-fetoprotein; BCLC, Barcelona Clinic Liver Cancer; b.i.d., twice daily; ECOG, Eastern Cooperative Oncology Group; EHS, extrahepatic spread; HBV, hepatitis B virus; HCV, hepatitis C virus; MVI, macrovascular invasion; PEI, percutaneous ethanol injection; TACE, transarterial chemoembolization. ${ }^{a}$ This patient with a ChildPugh score of 7 in the sorafenib group was a protocol deviation. 


\section{Liver Cancer}

Fig. 1. Geometric mean plasma concentration-time profiles of nintedanib, BIBF 1202, and BIBF 1202 glucuronide after multiple oral administrations of $200 \mathrm{mg}$ nintedanib b.i.d. to patients with advanced hepatocellular carcinoma (semi-log scale) for the phase I and phase II portions.

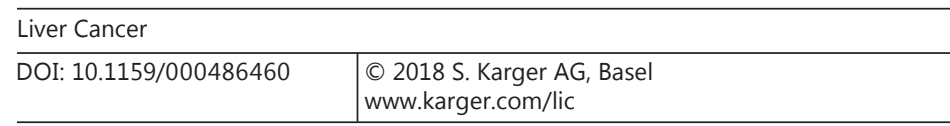

Yen et al.: Nintedanib versus Sorafenib in Asian Patients

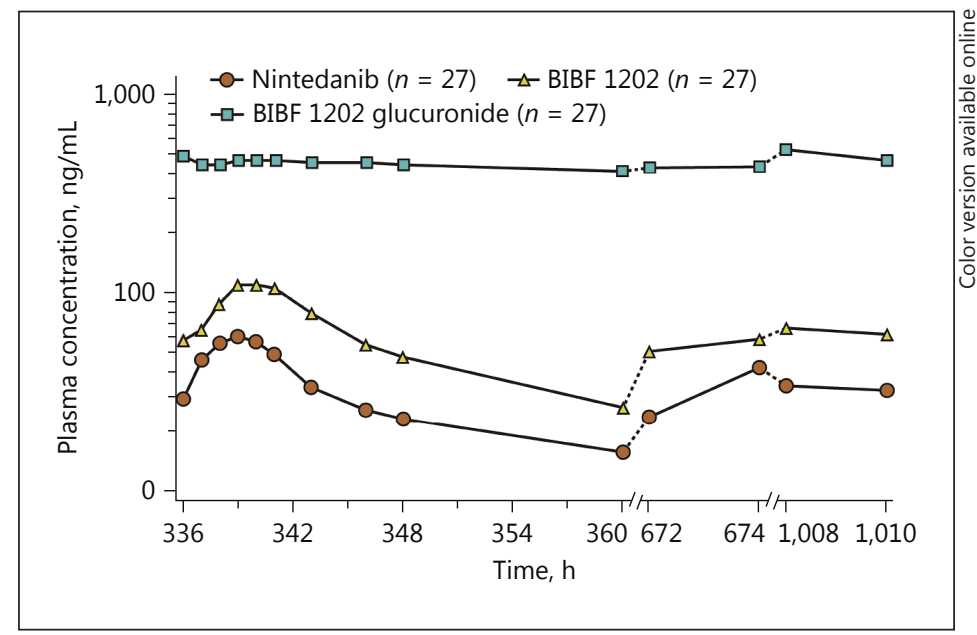

Patient Treatment Exposure

For phase II, the median treatment duration was 118 days in the nintedanib group versus 144 days in the sorafenib group. The mean dose intensity was $97.6 \%$ in the nintedanib group versus $81.9 \%$ in the sorafenib group. Online supplementary Table S1 summarizes the nintedanib dose reductions and exposure for phase I.

\section{Determination of MTD}

There were no DLTs during the MTD determination period (i.e., first 28 days) in group I at any dose up to $200 \mathrm{mg}$ b.i.d. One DLT was reported with $100 \mathrm{mg}$ b.i.d. (grade 3 AST increase) and no DLT in the first 3 patients with $200 \mathrm{mg}$ b.i.d. in group II. Since $200 \mathrm{mg}$ was the highest dose tested, the MTD was determined to be $200 \mathrm{mg}$ b.i.d. in both groups. DLTs experienced after the MTD determination period are described in the online supplementary material.

\section{Pharmacokinetics}

Plasma and urine samples of 55 patients were included in the PK evaluation: 22 patients in group I (some of whom were phase II patients; 3 patients in the $100 \mathrm{mg}$ b.i.d. cohort, 3 patients in the $150 \mathrm{mg}$ b.i.d. cohort, and 16 patients in the $200 \mathrm{mg}$ b.i.d. cohort), and 23 patients in group II, including patients in the extension cohort ( 3 patients in the $50 \mathrm{mg}$ b.i.d. cohort, 6 patients in the $100 \mathrm{mg}$ b.i.d. cohort, 3 patients in the $150 \mathrm{mg}$ b.i.d. cohort, and 11 patients in the $200 \mathrm{mg}$ b.i.d. cohort). Group I PK evaluations included patients from the phase I and phase II parts of the study. Three patients (1 patient in the $100 \mathrm{mg}$ b.i.d. cohort and 2 patients in the $200 \mathrm{mg}$ b.i.d. cohort) were categorized as Child-Pugh B; all of the other patients were categorized as Child-Pugh A.

Nintedanib was rapidly absorbed followed by at least biphasic disposition kinetics (Fig. 1). Maximum plasma concentrations were achieved around a median of $3 \mathrm{~h}$ (Table 2). Trough plasma concentrations maintained a steady state throughout the observation period. BIBF 1202 plasma concentrations reached a maximum around a median of $3 \mathrm{~h}$ and also maintained steady state throughout the observation period. BIBF 1202 glucuronide plasma concentrations reached a plateau and stayed constant over the observation period.

The maximum concentration in plasma at steady state $\left(\mathrm{C}_{\text {max,ss }}\right)$ values as well as exposure in terms of area under the concentration-time curve between 0 and $12 \mathrm{~h}$ at steady state $\left(\mathrm{AUC}_{0-12, \mathrm{ss}}\right)$ values of nintedanib increased with increasing doses over the dose range tested (Table 2). High interpatient variability of PK parameters over all dose groups was observed. 


\section{Liver}

\begin{tabular}{l|l}
\hline Liver Cancer \\
\hline DOI: 10.1159/000486460 & $\begin{array}{l}\text { C } 2018 \text { S. Karger AG, Basel } \\
\text { www.karger.com/lic }\end{array}$ \\
\hline
\end{tabular}

Yen et al.: Nintedanib versus Sorafenib in Asian Patients

Table 2. gMean and gCV\% or individual pharmacokinetic parameters of nintedanib, BIBF 1202, and BIBF 1202 glucuronide after multiple oral administrations of nintedanib by dose group, for the phase I and phase II portions

\begin{tabular}{|c|c|c|c|c|}
\hline \multirow{2}{*}{$\begin{array}{l}\text { Pharmacokinetic } \\
\text { parameter }\end{array}$} & \multicolumn{4}{|c|}{ Nintedanib dose, gMean (gCV\%) } \\
\hline & 50 mg b.i.d. & 100 mg b.i.d. & 150 mg b.i.d. & 200 mg b.i.d. \\
\hline \multicolumn{5}{|l|}{ Nintedanib } \\
\hline \multirow[t]{2}{*}{$\mathrm{C}_{\max , \mathrm{ss}}, \mathrm{nmol} / \mathrm{L}$} & $29.0(84.8)$ & $44.4(77.1)$ & $101(68.8)$ & $86.7(103)$ \\
\hline & $n=3$ & $n=9$ & $n=6$ & $n=27$ \\
\hline \multirow[t]{2}{*}{$\mathrm{C}_{\text {max,ss,norm }}, \mathrm{nmol} / \mathrm{L} / \mathrm{mg}$} & $0.579(84.8)$ & $0.444(77.1)$ & $0.676(68.8)$ & $0.434(103)$ \\
\hline & $n=3$ & $n=9$ & $n=6$ & $n=27$ \\
\hline \multirow[t]{2}{*}{$\mathrm{t}_{\max , \mathrm{ss}}{ }^{\mathrm{a}}, \mathrm{h}$} & $3.00(1.00-6.95)$ & $3.00(2.00-5.00)$ & $3.50(1.02-4.98)$ & $3.00(0-7.00)$ \\
\hline & $n=3$ & $n=9$ & $n=6$ & $n=27$ \\
\hline \multirow[t]{2}{*}{$\mathrm{AUC}_{0-12, \mathrm{ss}}, \mathrm{nmol} \times \mathrm{h} / \mathrm{L}$} & 220 & 277 (107) & $599(76.7)$ & $502(92.0)$ \\
\hline & $n=1$ & $n=7$ & $n=5$ & $n=27$ \\
\hline \multirow[t]{2}{*}{$\mathrm{AUC}_{0-12, \mathrm{ss}, \text { norm }}, \mathrm{nmol} \mathrm{h} / \mathrm{L} / \mathrm{mg}$} & 4.40 & 2.77 (107) & $3.99(76.7)$ & $2.51(92.0)$ \\
\hline & $n=1$ & $n=7$ & $n=5$ & $n=27$ \\
\hline \multirow[t]{2}{*}{$\mathrm{Ae}_{0-12, \mathrm{ss}}, \mu \mathrm{g}$} & $134(14.5)$ & 302 (63.7) & $414(82.7)$ & $473(78.2)$ \\
\hline & $n=3$ & $n=9$ & $n=6$ & $n=27$ \\
\hline \multirow[t]{2}{*}{$\mathrm{fe}_{0-12, \mathrm{ss}}, \%$} & $0.268(14.5)$ & $0.302(63.7)$ & $0.276(82.7)$ & $0.237(78.2)$ \\
\hline & $n=3$ & $n=9$ & $n=6$ & $n=27$ \\
\hline \multirow[t]{2}{*}{$\mathrm{CL}_{\mathrm{R}, \mathrm{ss}}, \mathrm{mL} / \mathrm{min}$} & 9.87 & $18.8(57.6)$ & $11.9(78.0)$ & $15.7(44.8)$ \\
\hline & $n=1$ & $n=7$ & $n=5$ & $n=27$ \\
\hline \multicolumn{5}{|l|}{ BIBF 1202} \\
\hline \multirow[t]{2}{*}{$\mathrm{C}_{\text {max }, \mathrm{ss}, \text { norm }}, \mathrm{nmol} / \mathrm{L} / \mathrm{mg}$} & $0.840(219)$ & $0.736(156)$ & $0.988(98.1)$ & $0.667(151)$ \\
\hline & $n=3$ & $n=9$ & $n=6$ & $n=27$ \\
\hline \multirow[t]{2}{*}{$\mathrm{t}_{\max , \mathrm{ss}}{ }^{\mathrm{a}}, \mathrm{h}$} & $4.00(2.00-6.95)$ & $3.07(2.00-7.02)$ & $4.01(2.00-5.00)$ & $3.00(0.00-7.00)$ \\
\hline & $n=3$ & $n=7$ & $n=6$ & $n=27$ \\
\hline \multirow[t]{2}{*}{$\mathrm{AUC}_{0-12, \mathrm{ss}, \text { norm }}, \mathrm{nmol} \times \mathrm{h} / \mathrm{L} / \mathrm{mg}$} & 27.2 & $5.89(209)$ & $8.32(128)$ & $4.83(149)$ \\
\hline & $n=1$ & $n=7$ & $n=5$ & $n=27$ \\
\hline \multicolumn{5}{|l|}{ BIBF 1202 glucuronide } \\
\hline \multirow[t]{2}{*}{$\mathrm{C}_{\text {max }, \mathrm{ss}, \text { norm }}, \mathrm{nmol} / \mathrm{L} / \mathrm{mg}$} & $2.22(300)$ & $1.45(192)$ & $3.26(121)$ & $2.59(144)$ \\
\hline & $n=3$ & $n=9$ & $n=6$ & $n=27$ \\
\hline \multirow[t]{2}{*}{$\mathrm{t}_{\max , \mathrm{ss}}{ }^{\mathrm{a}}, \mathrm{h}$} & $3.00(1.02-11.0)$ & $7.00(0-11.0)$ & $2.00(0-10.0)$ & $3.00(0-11.0)$ \\
\hline & $n=3$ & $n=9$ & $n=6$ & $n=27$ \\
\hline \multirow[t]{2}{*}{$\mathrm{AUC}_{0-12, \mathrm{ss}, \text { norm }}, \mathrm{nmol} \times \mathrm{h} / \mathrm{L} / \mathrm{mg}$} & 137 & $18.0(240)$ & 37.1 (138) & $27.5(141)$ \\
\hline & $n=1$ & $n=7$ & $n=5$ & $n=27$ \\
\hline
\end{tabular}

$\mathrm{Ae}_{0-12, \mathrm{ss}}$, amount of analyte eliminated in urine at steady state over the time interval $0-12 \mathrm{~h} ; \mathrm{AUC}_{0-12, \mathrm{ss}}$, area under the concentration-time curve between 0 and $12 \mathrm{~h}$ at steady state; b.i.d., twice daily; $\mathrm{CL}_{\mathrm{R}, \mathrm{ss}}$, renal clearance of the analyte at steady state based on 0 - to 12 -h data; $C_{m a x, s s}$, maximum concentration in plasma at steady state; fe ${ }_{0-12, s s}$, fraction of analyte excreted unchanged in urine at steady state over the time interval 0-12 h; gCV, geometric mean of the coefficient of variation; gMean, geometric mean; norm, normalized; $\mathrm{t}_{\text {max,ss }}$, time to reach $\mathrm{C}_{\max , \mathrm{ss} \cdot}{ }^{\mathrm{a}}$ Median (range).

The dose-normalized exposure parameters $\left(\mathrm{C}_{\mathrm{max}, \mathrm{ss}, \mathrm{norm}}\right.$ and $\left.\mathrm{AUC}_{0-12, \mathrm{ss}, \text { norm }}\right)$ generally remained constant over the different dose groups, taking into account differences in patient numbers between dose groups and the high variability of PK parameters. Renal elimination of nintedanib was low. Twelve hours after repeated dose administration, between 0.237 and $0.302 \%$ of the administered dose was recovered in urine ( $\left.\mathrm{fe}_{0-12, \mathrm{ss}}\right)$. Renal clearance $\left(\mathrm{CL}_{\mathrm{R}, \mathrm{ss}}\right)$ of nintedanib was low (9.87-18.8 $\mathrm{mL} / \mathrm{min}$ ) and did not change with the dose administered. Exposure to the two major metabolites of nintedanib, BIBF 1202 and BIBF 1202 glucuronide, generally increased in proportion to the nintedanib dose, taking the high variability into account (Table 2). 


\section{Liver}

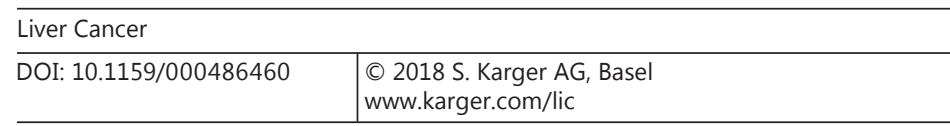

Yen et al.: Nintedanib versus Sorafenib in Asian Patients

We observed a trend towards an increased geometric mean (gMean) exposure to nintedanib, BIBF 1202, and BIBF 1202 glucuronide in patients with HCC in group II compared to group I (online suppl. Table S2). However, the range of individual values strongly overlapped when data from both groups were compared. When data from Asian patients with HCC in either Child-Pugh category A or B were compared, a similar trend was observed; however, the number of patients in Child-Pugh category B was very low.

There was no relevant effect of HCC on plasma protein binding of nintedanib, neither for patients in group I or group II nor for patients in Child-Pugh category A. Because of the low number of patients in Child-Pugh category B, firm conclusions on the effect of liver impairment on nintedanib protein binding cannot be made. The overall mean plasma protein binding of nintedanib was comparable between HCC patients and control healthy volunteer samples with mean bound fraction values of $98.3 \pm 1.3 \%$ and $97.4 \pm 1.4 \%$, respectively. Corresponding mean unbound fractions were at $1.70 \pm 1.31 \%$ and $2.67 \pm 1.42 \%$, respectively. The mean protein binding between patient groups I and II was comparable, with unbound fractions ranging from 1.28 to $2.03 \%$. The free fraction observed in samples from patients assigned to Child-Pugh category A was also comparable to those observed in groups I and II, with a mean unbound fraction of $1.72 \pm 1.32 \%$. The protein unbound fraction in samples from patients assigned to Child-Pugh category B was $0.997 \%$ (sample from 1 patient). The number of samples was limited, but the unbound fraction value was within the range of variability observed for the other patient subpopulations as well as for the healthy volunteer controls.

\section{Efficacy}

For the phase II primary endpoint, median TTP according to RECIST v1.0 by CIR was 2.8 months (95\% CI 1.8-3.7) for nintedanib versus 3.7 months (95\% CI 1.9-7.3) for sorafenib (HR $=1.21,95 \%$ CI 0.73-2.01) (Fig. 2a). For the secondary endpoints, median OS was 10.2 months (95\% CI 6.8-13.0) for nintedanib versus 10.7 months (95\% CI 7.5-12.4) for sorafenib (HR $=0.94,95 \%$ CI 0.59-1.49) (Fig. 2b). Median PFS by CIR according to RECIST v1.0 was 2.7 months $(95 \%$ CI 1.8-3.7) for nintedanib and 3.7 months (95\% CI 1.9-7.3) for sorafenib (HR $=1.19,95 \%$ CI 0.73-1.93) (Fig. 2c). Online supplementary Table S3 shows the best overall response according to RECIST and modified RECIST by CIR, including the secondary endpoint objective tumor response according to RECIST by CIR. Of the patients who were treated beyond RECIST progression, 12 (19.0\%) were taking nintedanib and 9 $(28.1 \%)$ were taking sorafenib. One patient in the nintedanib group who was treated beyond PD was treated for a total of 1,038 days; 2 patients out of the ones treated beyond PD had a partial response and were treated for 634 days and 132 days in total.

The phase II exploratory endpoint results are presented in the online supplementary material.

\section{Safety and Tolerability}

The phase I safety results are presented in the online supplementary material. Table 3 provides an overall summary of AEs occurring during the phase II portion. A total of 31 patients had AEs leading to dose reduction, $12(19.0 \%)$ in the nintedanib group and 19 $(59.4 \%)$ in the sorafenib group. Of the patients who had AEs leading to drug discontinuation, $15(23.8 \%)$ were in the nintedanib group and 11 (34.4\%) in the sorafenib group. Fewer

Fig. 2. Phase II Kaplan-Meier curves of TTP by central independent review assessed according to Response Evaluation Criteria in Solid Tumors v1.0 (a), OS (b), and PFS (c). CI, confidence interval; OS, overall survival; PFS, progression-free survival; TTP, time to progression.

(For figure see next page.) 
a

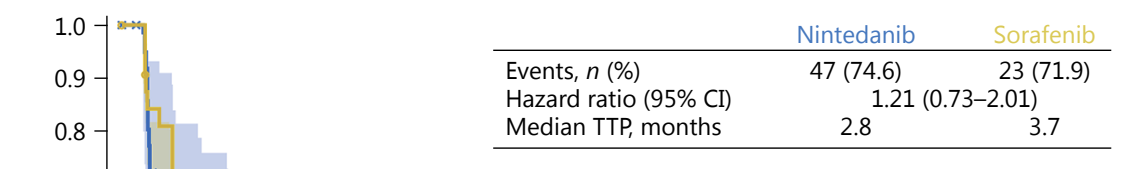

Nintedanib

Sorafenib

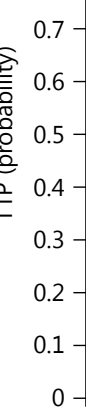

b

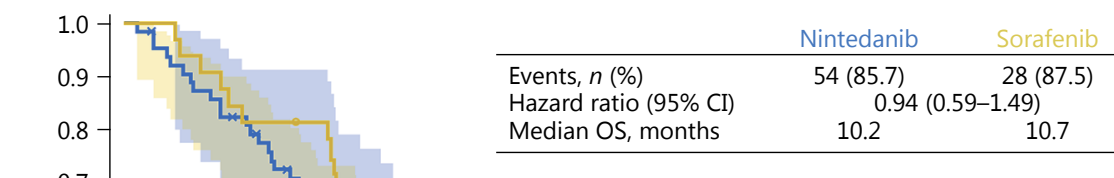

Time, months

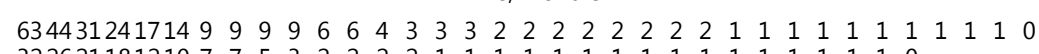
$32262118121077 \begin{array}{llllllllllllllllllllllll} & 5 & 5 & 2 & 2 & 2 & 2 & 1 & 1 & 1 & 1 & 1 & 1 & 1 & 1 & 1 & 1 & 1 & 1 & 1 & 1 & 1 & 1 & 0\end{array}$

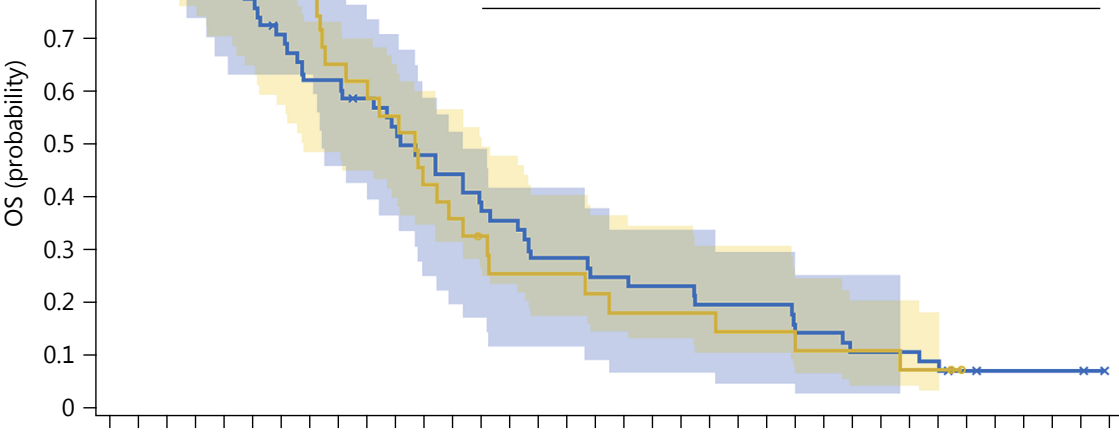

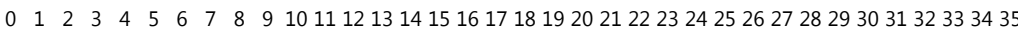

No. at risk Nintedanib Sorafenib

\section{Time, months}

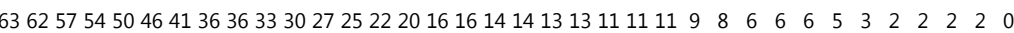

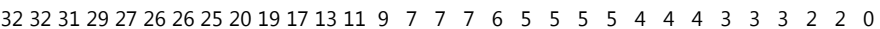

C

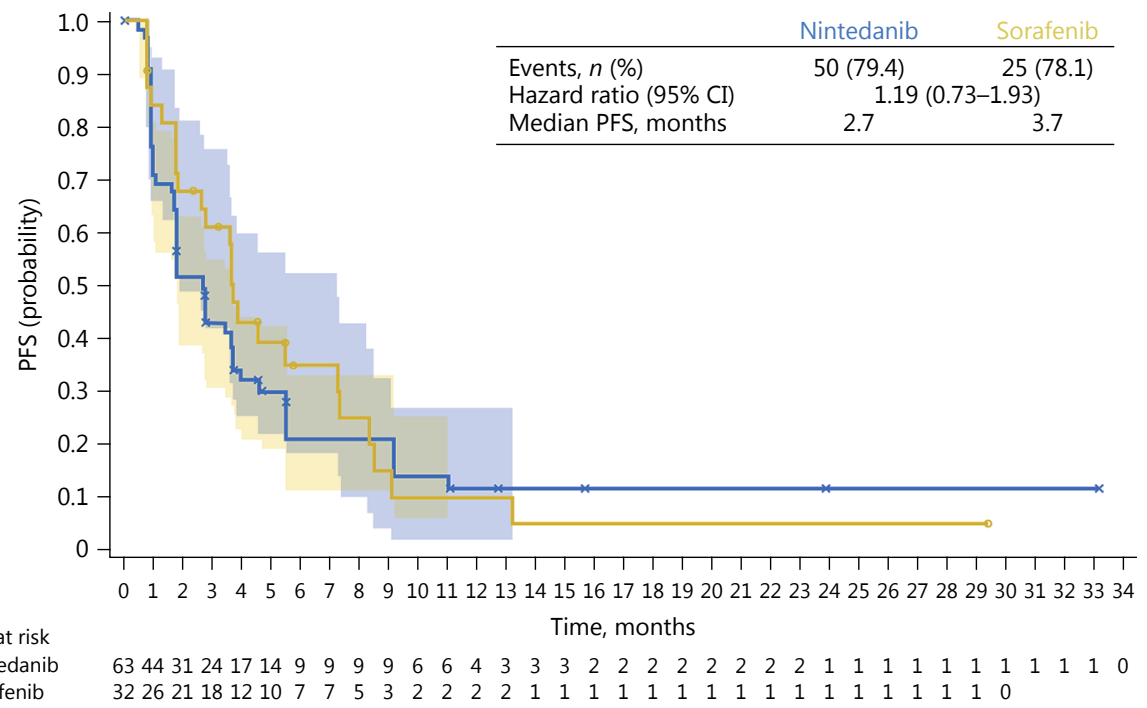




\section{Liver
Cancer}

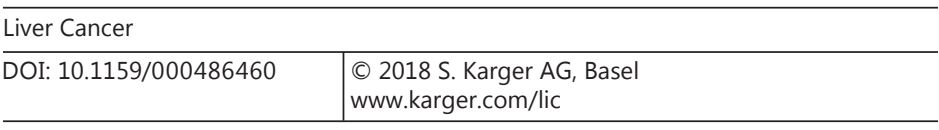

Yen et al.: Nintedanib versus Sorafenib in Asian Patients

Table 3. Phase II overall summary of AEs (CTCAE v3.0)

\begin{tabular}{|c|c|c|c|c|}
\hline \multirow[t]{3}{*}{ Characteristic } & \multicolumn{4}{|c|}{ Treatment group } \\
\hline & \multicolumn{2}{|c|}{$\begin{array}{l}\text { nintedanib } 200 \mathrm{mg} \\
\text { b.i.d. }(n=63)\end{array}$} & \multicolumn{2}{|c|}{$\begin{array}{l}\text { sorafenib } 400 \mathrm{mg} \\
\text { b.i.d. }(n=32)\end{array}$} \\
\hline & $n$ & $\%$ & $n$ & $\%$ \\
\hline Patients with any $\mathrm{AE}$ & 62 & 98.4 & 32 & 100.0 \\
\hline Patients with investigator-defined drug-related AEs & 48 & 76.2 & 31 & 96.9 \\
\hline Patients with AEs leading to dose reduction of trial drug & 12 & 19.0 & 19 & 59.4 \\
\hline Patients with AEs leading to discontinuation of trial drug & 15 & 23.8 & 11 & 34.4 \\
\hline Patients with serious AEs & 29 & 46.0 & 18 & 56.3 \\
\hline Fatal & 10 & 15.9 & 4 & 12.5 \\
\hline Immediately life-threatening & 4 & 6.3 & 0 & 0.0 \\
\hline Disability/incapacitating & 0 & 0.0 & 0 & 0.0 \\
\hline Required hospitalization & 29 & 46.0 & 18 & 56.3 \\
\hline Prolonged hospitalization & 5 & 7.9 & 1 & 3.1 \\
\hline Congenital anomaly & 0 & 0.0 & 0 & 0.0 \\
\hline Other & 0 & 0.0 & 0 & 0.0 \\
\hline \multicolumn{5}{|l|}{ Worst CTCAE grade of AEs } \\
\hline Grade 1 & 12 & 19.0 & 1 & 3.1 \\
\hline Grade 2 & 15 & 23.8 & 4 & 12.5 \\
\hline Grade 3 & 17 & 27.0 & 18 & 56.3 \\
\hline Grade 4 & 8 & 12.7 & 5 & 15.6 \\
\hline Grade 5 & 10 & 15.9 & 4 & 12.5 \\
\hline
\end{tabular}

A patient may have been counted in more than one seriousness criterion. Percentages were calculated using the total number of patients per treatment as the denominator. MedDRA v17.0 was used for reporting. AE, adverse event; b.i.d., twice daily; CTCAE, Common Terminology Criteria for Adverse Events.

patients in the nintedanib than in the sorafenib group had investigator-defined drug-related AEs (76.2 vs. 96.9\%), serious AEs ( 46.0 vs. $56.3 \%$ ), and grade 3 or higher AEs (55.6 vs. $84.4 \%$ ). The most common AEs that led to dose reductions and drug discontinuations in the nintedanib and sorafenib groups during the phase II portion are presented in online supplementary Table S4.

AEs associated with VEGF pathway inhibition, and other any-grade AEs of special interest, included (for nintedanib versus sorafenib) specific liver-related investigations (tailored; 27.0 vs. $37.5 \%$ ), bleeding ( 27.0 vs. $31.3 \%$ ), rash (22.2 vs. $37.5 \%$ ), hypertension (15.9 vs. $21.9 \%$ ), cutaneous adverse reactions (3.2 vs. $15.6 \%$ ), thromboembolic events (3.2 vs. $3.1 \%$ ), and gastrointestinal perforation (1.6 vs. 3.1\%).

In terms of frequently occurring any-grade AEs by preferred term, diarrhea (56.3 vs. $46.0 \%$ ), palmar-plantar erythrodysesthesia syndrome (53.1 vs. 6.3\%), increased AST (34.4 vs. $15.9 \%$ ), abdominal pain (34.4 vs. $19.0 \%$ ), upper abdominal pain (34.4 vs. $22.2 \%$ ), rash (28.1 vs. $15.9 \%$ ), and increased ALT (21.9 vs. $11.1 \%$ ) were $>10 \%$ higher with sorafenib compared to nintedanib, whereas the incidence of any-grade decreased appetite (39.7 vs. $25.0 \%$ ), nausea (30.2 vs. $12.5 \%$ ), vomiting ( 30.2 vs. $15.6 \%$ ), abdominal distension ( 28.6 vs. $12.5 \%$ ), and ascites ( 22.2 vs. $9.4 \%$ ) was $>10 \%$ higher with nintedanib compared to sorafenib (Table 4). Table 4 also shows grade 3 or higher AEs in $\geq 5 \%$ of patients in either treatment group. In 14 patients, AEs led to death $(10$ [15.9\%] in the nintedanib group and 4 [12.5\%] in the sorafenib group), which was related to PD for all but 1 patient in each group (sepsis in the nintedanib group patient and acute coronary syndrome in the sorafenib group patient). 
Yen et al.: Nintedanib versus Sorafenib in Asian Patients

Table 4. Most frequently reported (patient level) AEs by primary system organ class and preferred term (occurring at any grade in $\geq 20 \%$ or at grade $\geq 3$ in $\geq 5 \%$ patients in either treatment group) during the phase II portion

\begin{tabular}{|c|c|c|c|c|c|c|c|c|}
\hline \multirow[t]{4}{*}{$\mathrm{AE}$} & \multicolumn{8}{|c|}{$\mathrm{AE}$ grade by treatment group } \\
\hline & \multicolumn{4}{|c|}{ nintedanib 200 mg b.i.d. $(n=63)$} & \multicolumn{4}{|c|}{ sorafenib $400 \mathrm{mg}$ b.i.d. $(n=32)$} \\
\hline & \multicolumn{2}{|l|}{ all } & \multicolumn{2}{|l|}{$\geq 3$} & \multicolumn{2}{|l|}{ all } & \multicolumn{2}{|l|}{$\geq 3$} \\
\hline & $n$ & $\%$ & $n$ & $\%$ & $n$ & $\%$ & $n$ & $\%$ \\
\hline Any & 62 & 98.4 & 35 & 55.6 & 32 & 100.0 & 27 & 84.4 \\
\hline Blood and lymphatic system disorders & 23 & 36.5 & 10 & 15.9 & 12 & 37.5 & 5 & 15.6 \\
\hline Anemia & 12 & 19.0 & 5 & 7.9 & 5 & 15.6 & 3 & 9.4 \\
\hline Thrombocytopenia & 12 & 19.0 & 5 & 7.9 & 7 & 21.9 & 2 & 6.3 \\
\hline Gastrointestinal disorders & 52 & 82.5 & 18 & 28.6 & 30 & 93.8 & 8 & 25.0 \\
\hline Diarrhea & 29 & 46.0 & 4 & 6.3 & 18 & 56.3 & 2 & 6.3 \\
\hline Nausea & 19 & 30.2 & 0 & 0.0 & 4 & 12.5 & 0 & 0.0 \\
\hline Vomiting & 19 & 30.2 & 0 & 0.0 & 5 & 15.6 & 0 & 0.0 \\
\hline Abdominal distension & 18 & 28.6 & 1 & 1.6 & 4 & 12.5 & 1 & 3.1 \\
\hline Abdominal pain upper & 14 & 22.2 & 0 & 0.0 & 11 & 34.4 & 0 & 0.0 \\
\hline Ascites & 14 & 22.2 & 4 & 6.3 & 3 & 9.4 & 0 & 0.0 \\
\hline Constipation & 13 & 20.6 & 0 & 0.0 & 7 & 21.9 & 0 & 0.0 \\
\hline Abdominal pain & 12 & 19.0 & 2 & 3.2 & 11 & 34.4 & 1 & 3.1 \\
\hline General disorders and administration site conditions & 38 & 60.3 & 6 & 9.5 & 19 & 59.4 & 4 & 12.5 \\
\hline Fatigue & 14 & 22.2 & 2 & 3.2 & 4 & 12.5 & 0 & 0.0 \\
\hline Pyrexia & 14 & 22.2 & 1 & 1.6 & 8 & 25.0 & 0 & 0.0 \\
\hline Asthenia & 7 & 11.1 & 0 & 0.0 & 5 & 15.6 & 2 & 6.3 \\
\hline Hepatobiliary disorders & 8 & 12.7 & 6 & 9.5 & 5 & 15.6 & 4 & 12.5 \\
\hline Hepatic failure & 2 & 3.2 & 1 & 1.6 & 2 & 6.3 & 2 & 6.3 \\
\hline Investigations & 20 & 31.7 & 10 & 15.9 & 17 & 53.1 & 12 & 37.5 \\
\hline Aspartate aminotransferase increased & 10 & 15.9 & 3 & 4.8 & 11 & 34.4 & 7 & 21.9 \\
\hline Alanine aminotransferase increased & 7 & 11.1 & 2 & 3.2 & 7 & 21.9 & 3 & 9.4 \\
\hline Blood bilirubin increased & 7 & 11.1 & 3 & 4.8 & 3 & 9.4 & 2 & 6.3 \\
\hline Lipase increased & 3 & 4.8 & 1 & 1.6 & 2 & 6.3 & 2 & 6.3 \\
\hline Metabolism and nutrition disorders & 30 & 47.6 & 9 & 14.3 & 17 & 53.1 & 7 & 21.9 \\
\hline Decreased appetite & 25 & 39.7 & 3 & 4.8 & 8 & 25.0 & 2 & 6.3 \\
\hline Hyponatremia & 2 & 3.2 & 2 & 3.2 & 2 & 6.3 & 2 & 6.3 \\
\hline $\begin{array}{l}\text { Neoplasms benign, malignant, and unspecified } \\
\text { (including cysts and polyps) }\end{array}$ & 10 & 15.9 & 9 & 14.3 & 4 & 12.5 & 3 & 9.4 \\
\hline Malignant neoplasm progression & 6 & 9.5 & 6 & 9.5 & 2 & 6.3 & 2 & 6.3 \\
\hline Respiratory, thoracic, and mediastinal disorders & 31 & 49.2 & 6 & 9.5 & 19 & 59.4 & 3 & 9.4 \\
\hline Cough & 18 & 28.6 & 0 & 0.0 & 11 & 34.4 & 0 & 0.0 \\
\hline Pleural effusion & 3 & 4.8 & 2 & 3.2 & 3 & 9.4 & 2 & 6.3 \\
\hline Skin and subcutaneous tissue disorders & 24 & 38.1 & 1 & 1.6 & 25 & 78.1 & 8 & 25.0 \\
\hline Rash & 10 & 15.9 & 0 & 0.0 & 9 & 28.1 & 1 & 3.1 \\
\hline Palmar-plantar erythrodysesthesia syndrome & 4 & 6.3 & 0 & 0.0 & 17 & 53.1 & 5 & 15.6 \\
\hline Skin reaction & 2 & 3.2 & 0 & 0.0 & 5 & 15.6 & 2 & 6.3 \\
\hline Vascular disorders & 11 & 17.5 & 5 & 7.9 & 7 & 21.9 & 1 & 3.1 \\
\hline Hypertension & 10 & 15.9 & 4 & 6.3 & 7 & 21.9 & 1 & 3.1 \\
\hline
\end{tabular}

$\mathrm{AE}$, adverse event; b.i.d., twice daily.

\section{Discussion}

The results of this trial suggest that nintedanib had similar efficacy to sorafenib, with a favorable and manageable AE profile, in patients in Asia with advanced HCC. In phase I, the MTD was determined to be $200 \mathrm{mg}$ b.i.d. in both groups, which was used for phase II (further discussion is presented in the online suppl. material). In phase II, the frequency of AEs leading 
to dose reductions and drug discontinuations, as well as grade 3 or higher AEs, was lower with nintedanib compared to sorafenib. Nintedanib AEs were manageable, largely related to the gastrointestinal tract, with fewer cases of rash, palmar-plantar erythrodysesthesia syndrome, and transaminase elevations than for sorafenib. The incidence of diarrhea was higher in the sorafenib group, but for other gastrointestinal AEs such as nausea and vomiting, the incidence was higher in the nintedanib group. High rates of vomiting and nausea have also been reported in patients receiving nintedanib for other types of cancer [15, 16]. Angiogenesis inhibitor class-specific AEs reported in $>15 \%$ of sorafenib-treated patients were hypertension and palmar-plantar erythrodysesthesia syndrome.

In phase I, the MTD was determined to be $200 \mathrm{mg}$ b.i.d. in the two groups divided according to liver enzyme values and Child-Pugh score at baseline. A trend towards increased exposure depending on baseline ALT/AST levels was observed for nintedanib and its metabolites. For the evaluated dose range, nintedanib was well tolerated, with reports of grade 1 and 2 liver enzyme elevations in the majority of patients.

The baseline characteristics of patients in both groups in the phase II portion were well balanced, with the exception of AFP (more in the nintedanib group in the $>20 \mu \mathrm{g} / \mathrm{L}$ group), BCLC stage (more stage B and less stage $\mathrm{C}$ in the nintedanib group), and more MVI in the nintedanib (48\%) compared to the sorafenib group (31\%), which may have had an impact on survival. A higher percentage of patients in the sorafenib versus the nintedanib group had treatment beyond PD, which may have impacted the treatment/OS duration. Although responses were evaluated by RECIST, a post hoc analysis of data pooled from this trial and the companion trial conducted in Caucasian patients found that response according to RECIST or modified RECIST was associated with improved survival [17].

The rates of any-grade drug-related AEs for sorafenib were generally similar to those in the Asia-Pacific trial, with the notable exception of lower rates of diarrhea in the Asia-Pacific trial (25.5 vs. $46.9 \%$ in the present trial) [1]. As in the Asia-Pacific trial, patients in this trial were exclusively Asian, and approximately two-thirds were infected with HBV. In contrast to the Asia-Pacific trial, however, which reported a median OS of 6.5 months for patients treated with sorafenib, patients on sorafenib in the present trial had a median OS of 10.7 months, which was similar to that of the patients treated with nintedanib (10.2 months). Possible reasons that could account for this difference are stage migration and, of particular relevance to an open-label trial such as the present one (although difficult to prove), improved expertise for managing the sorafenib-associated toxicities. Consistent with both the SHARP [9] and Asia-Pacific [1] trials, the response rate for sorafenib was very low, despite prolonged survival compared to placebo seen in both Asian and Caucasian patients.

Of note is the length of time some patients remained on nintedanib. The 2 patients receiving nintedanib for the longest time in phase II were men with a total treatment time of 1,564 days based on updated data (1,038 days at data cutoff) and 725 days. Both patients had HBV-related HCC, BCLC stage C, and AFP $>20 \mu \mathrm{g} / \mathrm{L}$. Since they had early PD after nintedanib treatment, they were further treated beyond PD. In phase I group II, there was also a 61-year-old male patient (HCV-related HCC, BCLC stage C, AFP $\leq 20 \mu \mathrm{g} / \mathrm{L}$ ) with a total treatment time of 1,134 days (868 days at data cutoff).

Compared to mainly Caucasian patients from the similarly designed European phase I study (unpublished data), the PK data showed a slightly higher exposure to nintedanib in Asian patients.

The trial has several limitations. The exploratory nature of the study limits any firm conclusions regarding comparisons between the study drugs. The correlation between TTP and PFS with OS still needs to be established. Some patients received prophylactic antiviral therapy against HBV, yet stratification by such therapy was not performed, possibly confounding the interpretation of results $[18,19]$. In contrast with sorafenib, nintedanib 
shows activity against FGF, but the FGF status of patients was not assessed. Given the molecular heterogeneity of HCC that could mask activity of a drug in unselected populations $[6,20,21]$ and the crucial role played by FGF in liver carcinogenesis [8], targeted studies could examine the response to nintedanib in FGF-enriched populations.

In conclusion, the current trial suggests that nintedanib may have similar efficacy to sorafenib in patients with advanced HCC, but with a different and manageable safety profile. A comparable trial (unpublished data) conducted in Europe in mostly Caucasians found similar results.

\section{Acknowledgments}

The authors thank the patients, their families, and the investigators who participated in this trial, as well as all the members of the study team. They also thank Caren Choi for her contribution in execution of the trial and data cleaning and analysis, in addition to her thorough reviews of the manuscript. Medical writing services and editorial support, supported financially by Boehringer Ingelheim, were provided by Steven Tresker of Cactus Communications during the preparation of this report.

\section{Statement of Ethics}

The trial protocol was reviewed by the institutional review boards of the participating centers and conformed to the Helsinki Declaration. All patients provided written informed consent.

\section{Disclosure Statement}

A.-B. Loembé, D.C.-L. Huang, D. Schnell, and J. Hocke are employees of Boehringer Ingelheim. C.-J. Yen, T.-Y. Kim, Y.-H. Feng, Y. Chao, D.-Y. Lin, B.-Y. Ryoo, and A.-L. Cheng report no conflicts of interest.

\section{Funding Sources}

This study was supported by Boehringer Ingelheim.

\section{References}

1 Cheng AL, Kang YK, Chen Z, Tsao CJ, Qin S, Kim JS, Luo R, Feng J, Ye S, Yang TS, Xu J, Sun Y, Liang H, Liu J, Wang J, Tak WY, Pan H, Burock K, Zou J, Voliotis D, Guan Z: Efficacy and safety of sorafenib in patients in the AsiaPacific region with advanced hepatocellular carcinoma: a phase III randomised, double-blind, placebocontrolled trial. Lancet Oncol 2009;10:25-34.

-2 Yuen MF, Hou JL, Chutaputti A; Asia Pacific Working Party on Prevention of Hepatocellular Carcinoma: Hepatocellular carcinoma in the Asia pacific region. J Gastroenterol Hepatol 2009;24:346-353.

-3 El-Serag HB: Epidemiology of viral hepatitis and hepatocellular carcinoma. Gastroenterology 2012;142:12641273.e1.

4 Semela D, Dufour JF: Angiogenesis and hepatocellular carcinoma. J Hepatol 2004;41:864-880.

5 Chan SL, Yeo W: Targeted therapy of hepatocellular carcinoma: present and future. J Gastroenterol Hepatol 2012;27:862-872.

6 Whittaker S, Marais R, Zhu AX: The role of signaling pathways in the development and treatment of hepatocellular carcinoma. Oncogene 2010;29:4989-5005.

7 Zhu AX, Duda DG, Sahani DV, Jain RK: HCC and angiogenesis: possible targets and future directions. Nat Rev Clin Oncol 2011;8:292-301.

8 Sandhu DS, Baichoo E, Roberts LR: Fibroblast growth factor signaling in liver carcinogenesis. Hepatology 2014;59:1166-1173. 
Yen et al.: Nintedanib versus Sorafenib in Asian Patients

Llovet JM, Ricci S, Mazzaferro V, Hilgard P, Gane E, Blanc JF, de Oliveira AC, Santoro A, Raoul JL, Forner A, Schwartz M, Porta C, Zeuzem S, Bolondi L, Greten TF, Galle PR, Seitz JF, Borbath I, Häussinger D, Giannaris T, Shan M, Moscovici M, Voliotis D, Bruix J; SHARP Investigators Study Group: Sorafenib in advanced hepatocellular carcinoma. N Engl J Med 2008;359:378-390.

10 Abou-Alfa GK, Venook AP: The antiangiogenic ceiling in hepatocellular carcinoma: does it exist and has it been reached? Lancet Oncol 2013;14:e283-e288.

11 Bertino G, Di Carlo I, Ardiri A, Calvagno GS, Demma S, Malaguarnera G, Bertino N, Malaguarnera M, Toro A, Malaguarnera M: Systemic therapies in hepatocellular carcinoma: present and future. Future Oncol 2013;9: 1533-1548.

12 Hilberg F, Roth GJ, Krssak M, Kautschitsch S, Sommergruber W, Tontsch-Grunt U, Garin-Chesa P, Bader G, Zoephel A, Quant J, Heckel A, Rettig WJ: BIBF 1120: triple angiokinase inhibitor with sustained receptor blockade and good antitumor efficacy. Cancer Res 2008;68:4774-4782.

13 Kudo K, Arao T, Tanaka K, Nagai T, Furuta K, Sakai K, Kaneda H, Matsumoto K, Tamura D, Aomatsu K, De Velasco MA, Fujita Y, Saijo N, Kudo M, Nishio K: Antitumor activity of BIBF 1120, a triple angiokinase inhibitor, and use of VEGFR2+pTyr+ peripheral blood leukocytes as a pharmacodynamic biomarker in vivo. Clin Cancer Res 2011;17:1373-1381.

-14 Stopfer P, Rathgen K, Bischoff D, Ludtke S, Marzin K, Kaiser R, Wagner K, Ebner T: Pharmacokinetics and metabolism of BIBF 1120 after oral dosing to healthy male volunteers. Xenobiotica 2011;41:297-311.

15 Ledermann JA, Hackshaw A, Kaye S, Jayson G, Gabra H, McNeish I, Earl H, Perren T, Gore M, Persic M, Adams M, James L, Temple G, Merger M, Rustin G: Randomized phase II placebo-controlled trial of maintenance therapy using the oral triple angiokinase inhibitor BIBF 1120 after chemotherapy for relapsed ovarian cancer. J Clin Oncol 2011;29:3798-3804.

16 Reck M, Kaiser R, Mellemgaard A, Douillard JY, Orlov S, Krzakowski M, von Pawel J, Gottfried M, Bondarenko I, Liao M, Gann CN, Barrueco J, Gaschler-Markefski B, Novello S; LUME-Lung 1 Study Group: Docetaxel plus nintedanib versus docetaxel plus placebo in patients with previously treated non-small-cell lung cancer (LUME-Lung 1): a phase 3, double-blind, randomised controlled trial. Lancet Oncol 2014;15:143-155.

17 Meyer T, Palmer DH, Cheng AL, Hocke J, Loembe AB, Yen CJ: mRECIST to predict survival in advanced hepatocellular carcinoma: analysis of two randomised phase II trials comparing nintedanib versus sorafenib. Liver Int 2017;37:1047-1055.

18 Chen PJ, Furuse J, Han KH, Hsu C, Lim HY, Moon H, Qin S, Ye SL, Yeoh EM, Yeo W: Issues and controversies of hepatocellular carcinoma-targeted therapy clinical trials in Asia: experts' opinion. Liver Int 2010;30:14271438.

19 Yeo W, Chen PJ, Furuse J, Han KH, Hsu C, Lim HY, Moon H, Qin S, Yeoh EM, Ye SL: Eastern Asian expert panel opinion: designing clinical trials of molecular targeted therapy for hepatocellular carcinoma. BMC Cancer 2010;10:620.

20 Bolos D, Finn RS: Systemic therapy in HCC: lessons from brivanib. J Hepatol 2014;61:947-950.

-21 Villanueva A, Llovet JM: Impact of intra-individual molecular heterogeneity in personalized treatment of hepatocellular carcinoma. Hepatology 2012;56:2416-2419.

22 Lencioni R, Llovet JM: Modified RECIST (mRECIST) assessment for hepatocellular carcinoma. Semin Liver Dis 2010;30:52-60. 